Both Tan et al and Svanegaard et $a l^{1}$ found that initially raised plasma atrial natriuretic peptide concentrations in patients with myocardial infarction fell soon after admission. The extent of the fall found by Tan et al is unclear. Despite this fall plasma atrial natriuretic peptide concentrations remained raised in the patients reported by Svanegaard et al especially when cardiac failure was present. ${ }^{1}$ This fall in plasma atrial natriuretic peptide may reflect the beneficial effect of treatment (for example, bed rest, diuretics, glyceryl trinitrate, analgesia, thrombolysis) on left ventricular function as well as the initial depletion of atrial storage granules. Not enough detail is given by these other workers for us to comment further on the cause of the fall. Depletion of storage granules, however, seems to be an unlikely mechanism, because plasma atrial natriuretic peptide concentrations fell in all patients irrespective of the initial atrial natriuretic peptide concentration.

We agree with Tan et al that both the timing of the blood sample and the degree of infarction are important variables in interpreting plasma atrial natriuretic peptide concentrations. Indeed we found that in an experimental model of myocardial infarction the concentration of plasma atrial natriuretic peptide correlated well not only with the haemodynamic changes but also with the degree of infarction measured histologically. ${ }^{2}$ In this experimental model it was also possible to show an inverse relation between plasma atrial natriuretic peptide and atrial atrial natriuretic peptide. That we did not find a relation between peak concentrations of cardiac enzymes and plasma atrial natriuretic peptide in our human study was probably the result of the confounding effects of streptokinase treatment, which increased peak enzyme concentrations but lowered plasma atrial natriuretic peptide, and the inclusion of patients with ischaemic chest pain who had normal concentrations of cardiac enzyme but intermediate concentrations of plasma atrial natriuretic peptide, as well as the variable times of blood sampling (7-32 hours after admission). This underscores the difficulty of studying and interpreting the dynamics and mechanism of atrial natriuretic peptide release in patients with heart disease.

The finding of raised concentrations of plasma atrial natriuretic peptide during the acute stage of myocardial infarction before appreciable volume expansion could occur suggests that acute myocardial dysfunction alone may raise plasma atrial natriuretic peptide concentrations, probably by reducing ventricular compliance and increasing atrial pressures. This may be a beneficial homoeostatic response that acts to reduce cardiac preload and limit salt and water retention during the acute stages of myocardial ischaemia.

\section{P A Phillips,}

G P Hodsman,

C I Johnston,

Department of Medicine, University of Melbourne, Austin Hospital, Heidelberg, Victoria 3084, Australia.

\section{References}

1 Svanegaard J, Angelo-Nielsen K, Pindborg T. Atrial natriuretic peptide and acute myocardial infarction. Am Heart J 1989;117:194-5.

2 Tsunoda K, Hodsman GP, Sumithran E, et al. Atrial natriuretic peptide in chronic heart failure in the rat: a correlation with ventricular dysfunction. Circ Res 1986;59:256-61.

\title{
Pulmonary capillary haemangiomatosis
}

Sir,

A registry is being formed to document and study cases of pulmonary capillary haemangiomatosis, an exceptionally rare disease (only eight cases have been described) that leads to proliferation of capillaries in the lung and pulmonary hypertension. Anyone knowing of patients with this disorder is asked to contact either (1) CANADA and EUROPE: Dr David Langleben, Jewish General Hospital, 3755 Côte St Catherine, Montreal, Quebec H3T 1E2, Canada; or (2) USA, MIDDLE EAST, and ORIENT: Dr Carl W White, Division of Pulmonary
Disease, The Children's Hospital, 1956 East 19th Avenue, Denver, Colorado 80218-1088, USA. Strict confidentiality will be maintained and a newsletter will be circulated to all contributors.

David Langleben,

Jewish General Hospital, 3755 Côte St Catherine,

Montreal,

Quebec H3T 1E2,

Canada. 